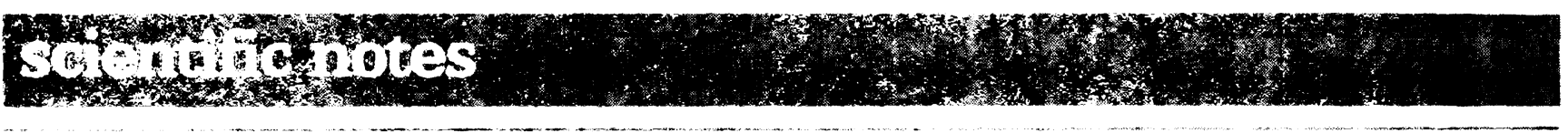

CLIN. CHEM. 34/3, 554-556 (1988)

\title{
Excretion of Digoxin-like Immunoreactivity in Urine of Normal Subjects: Correlations with Excretion of Creatinine and Electrolytes
}

\author{
Addo Clerlco, Ottevio Giampletro, Glovanna Cregorl, Marta Grazia Del Chicca, Stetania Bertoll, Roberto Mlccoll, and Renzo Navaloel
}

To verify whether there is a variation in the 24-h urinary excretion of digoxin-like immunoreactivity (DLIS) in humans, we studied 18 normal adults, who collected their urines for 24-h in several portions. We then measured DLIS (by means of a sensitive RIA method), creatinine, sodium, and potassium concentrations in the urine samples. The mean urinary excretion rate for DLIS in the complete 24-h collection was 84.8 (SD 31.3) pg/min. The mean DLIS urinary excretion rate calculated for ovemight collections was significantly lower than those of aftemoon collections $(P<0.01)$ and the 24-h collection $(P<0.05)$. Significant positive correlations were found between urinary DLIS and excretion rates for creatinine $(r=0.347, P=0.0016), \mathrm{Na}^{+}(r=0.232, P=0.038)$, and $\mathrm{K}^{+}$ ( $r=0.323, P=0.003$ ), respectively. Our data suggest that urinary excretion of DLIS is higher during "active" hours of the day, especially in the afternoon, than at rest, during the night.

Additional Keyphrases: radioimmunoassay - digitalis-like substances - cardiac glycosides - renal function

Several studies have documented the presence of an endogenous factor with digoxin-like immunoreactivity (Dus) in blood of experimental animals and humans, as determined with digoxin RIA or enzyme immunoassay methods for digoxin (for a review, see references 1-5). Experimental studies and theoretical considerations suggest that Dus might also be an endogenous modulator for $\mathrm{Na}^{+} / \mathrm{K}^{+}$-ATPase (the receptor of cardiac glycosides) and could play a role in the regulation of fluids and electrolytes, and in the pathogenesis of hypertension $(1,3,4)$.

Durs concentrations in plasma or serum of normal adult subjects are frequently close to the limit of sensitivity of RIA methods (6-8). Therefore, such samples are generally concentrated to improve the precision of the assay in studies of normal adult subjects. On the other hand, because Dus concentrations in urine samples of adults and newborns are four- to sixfold greater than in plasma samples, direct RIA could be preferable for urine samples (8). However, studies on the variation in 24-h urinary excretion of Dus in normal subjects have not been reported.

Here we report the urinary excretion rate of Dus in 18 normal subjects, as measured by a sensitive RIA method in which digoxin added to a buffer solution containing serum albumin serves as the standard. In addition, we investigated whether there are variations of urinary Dus excretion

Cattedra di Malattie del Ricambio, Istituto di Clinica Medica II, C.N.R. Institute of Clinical Physiology, University of Pisa, Via Savi 8, 56100 Pisa, Italy.

Received July 23, 1987; accepted December 7, 1987. throughout the day and if the urinary Dus values in normal adult subjects are correlated with urinary creatinine and electrolytes, as previously reported for newborns and boys $(9,10)$.

\section{Materlals and Methods}

Dus assay. We measured Dus by a previously reported solid-phase RIA method $(7,8)$. In this method, digoxin dissolved in a buffer containing $40 \mathrm{~g}$ of human serum albumin per liter is used as standard, ${ }^{126}$ I-labeled digoxin is the tracer, and a solid phase (antibody coated test-tubes) is used for separating bound digoxin from free. To improve the sensitivity and the reproducibility of the assay as well as the stability of standard curves, we used an assay buffer containing human serum albumin, $40 \mathrm{~g} / \mathrm{L}$. The same albumincontaining buffer was added to unknown urine samples to equalize the influence of albumin in the reaction volume (8). Results are expressed as digoxin equivalents.

We directly assayed $0.2-\mathrm{mL}$ samples of urine. The mean sensitivity obtained in 20 separate experiments, performed during nine months, was 2.98 (SD 1.11) pg per tube. The mean intra-assay CV (precision profile) ranged between $4 \%$ and $20 \%$ (range of the assay: $50-500 \mathrm{ng} / \mathrm{L}$ ), as previously reported (8). In addition, the mean between-assay CVs, tested during 10 months $(n=25)$ with two different urine pools, were $12.9 \%$ (digoxin equivalent, mean $\pm \mathrm{SD}, 281.9$ $\pm 36.4 \mathrm{ng} / \mathrm{L})$ and $19.5 \%(120.0 \pm 23.4 \mathrm{ng} / \mathrm{L})$, respectively. In addition, assaying increasing volumes of one urine pool gave a linear response (from 25 to $250 \mathrm{ng} / \mathrm{L}$ ), as previously reported (8). The mean Dus concentration in 62 plasma samples from normal subjects was 15.7 (SD 8.8) ng/L (range $\left.0 \_32 \mathrm{ng} / \mathrm{L}\right)$.

The antiserum we used cross reacts with digitoxin by $35 \%$, but negligibly $(<0.1 \%)$ with testosterone, progesterone, cortisone, aldosterone, estradiol, estriol, cholesterol, dehydroepiandrosterone, cortisol, prednisone, prednisolone, spironolactone, or ouabain, as previously reported (7).

Creatinine and electrolyte assays. Creatinine was measured colorimetrically with creatinine reagent kit $P / N$ 668306 (Astra System, Beckman Instruments, Inc., Galway, Ireland). Urinary sodium and potassium concentrations were measured with a Model 435 flame photometer (Corning Medical, Halsted, Essex, U.K.).

Subjects. We studied 18 normal, healthy subjects (10 women and eight men, ages 22-54 years, mean 29.1, SD 6.7 years), who collected their urines for $24 \mathrm{~h}$, in several portions. The first urine sample on the morning of the day of the 24-h collection (sample 0) was put in a separate container. Subsequently, the complete 24-h urinary collection consisted of: sample 1, from waking to lunch; sample 2, from lunch to dinner; sample 3, from dinner to bedtime; 


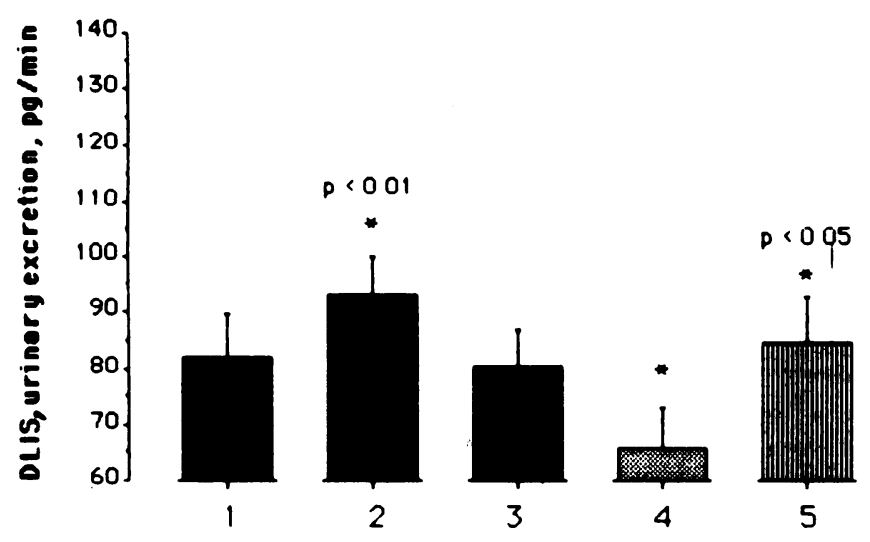

rig. 1. Mean ( $\pm S E M)$ urinary excretion rate of ous in the different portions of 24-h urine collected from the 18 subjects (see Table 1)

Table 1. DLIS/CR Ratios for the Different Specimens of Urine from 18 Normal Persons

\begin{tabular}{lcc} 
& \multicolumn{2}{c}{ DLIS(ng/L)/CR(g/L) ratlo } \\
\cline { 2 - 3 } Specimen & Moan & SD \\
O. First morning & $64.8^{\star}$ & 15.7 \\
1. Morning & 83.6 & 28.7 \\
2. Afternoon & 92.5 & 44.1 \\
3. Evening & 75.9 & 30.6 \\
4. Overnight & $68.2^{a}$ & 23.7 \\
5. 24 h (1-4) & 83.1 & 29.7 \\
- Significantly different ( $P$ <0.01, unpaired ttest) from 24-h collection \\
(sample 5).
\end{tabular}

sample 4, overnight, at rest. The volume of each portion was recorded, as was the time of collection. From each fraction we took three 1-mL aliquots, for assay of Dus, creatinine, and electrolytes. We then pooled urine fractions 1 to 4 , to yield the complete 24-h collection (sample 5). All samples were stored at $-20^{\circ} \mathrm{C}$ until assay. To minimize analytical error, we used the same lot of standard solutions, coatedtubes, and tracer solution in assaying the urine samples.

Durs and creatinine concentrations were measured in each portion of urine $(n=108)$; electrolytes were measured in the samples of 16 of the 18 subjects $(n=96)$. Finally, we calculated the urinary excretion rates of Dus ( $\mathrm{pg} / \mathrm{min}$ ), creatinine $(\mathrm{mg} / \mathrm{min})$, and electrolytes $(\mathrm{mmol} / \mathrm{min}$ ) on fractions 1 to $4(n=90)$, but not on sample 0 , which was not timed.

Statistical analysis. We calculated all sample values, the index of sensitivity, the precision profile, and the data for quality control of the RIA systems by means of previously described computer programs $(11,12)$. The interpolation of the dose-response curves was calculated by using a fourparameter logistic function (12).

For statistical analysis for comparison of mean values, and calculation of simple and multiple regression coefficients, we used a Macintosh SE personal computer and the $5_{12}{ }^{+}$Stat-View ${ }^{\text {TW }}$ program.

\section{Results}

Concentrations of Dus in all the urine samples ranged between 22.5 and $231.5 \mathrm{ng} / \mathrm{L}$ (mean $\pm \mathrm{SD}=114.1 \pm 43.8$ $\mathrm{ng} / \mathrm{L}, \mathrm{n}=108$ ). The mean Dus excretion rate for our subjects, calculated on the complete 24-h collection, was 84.8 (SD 31.3) $\mathrm{pg} / \mathrm{min}$, corresponding to a daily urinary excretion of 122 (SD 45) $\mathrm{ng} / 24 \mathrm{~h}$. The mean Dus urinary excretion rates, in samples 1 to 5 , differed significantly from portion to portion $(P<0.05$, ANOVA) (Figure 1). The value for the overnight collection (sample 4) was significantly lower than values for samples 2 (afternoon collection, $P<0.01$ ) and 5 (24-h collection, $P<0.05$ ).

We found a significant positive correlation between urinary Dus and creatinine concentrations (Dus $=107+0.33$ creatinine, $r=0.601, \mathrm{n}=108, P<0.001$ ). Table 1 lists the means of each Dus/creatinine concentration ratio (Dur/CR) obtained for the six different portions of 24-h urine (samples 0 to 5). Differences among the mean ratios in the six fractions were significant $(P<0.001$, ANOVA). Moreover, the DLIs/CR ratios found in urine fractions 0 to 4 correlated positively with the value of the complete 24-h collection (fraction 5), with $r$ ranging between 0.63 and $0.84(n=18, P$ $<0.001)$.

Weak positive correlations were found between the rates of urinary excretion of DLIs and of creatinine (DLIS $=72.7+$ 13.3 creatinine, $\mathrm{n}=80, r=0.347, P=0.002$ ), $\mathrm{Na}^{+}$(DLs = $72.5+4.5 \mathrm{Na}^{+}, r=0.232, \mathrm{n}=80, P<0.038$ ), and $\mathrm{K}^{+}$(Dus $=$ $72.6+146.0 \mathrm{~K}^{+}, r=0.323, \mathrm{n}=80, P=0.004$ ). Stepwise multiple-regression analysis among $\mathrm{K}^{+}, \mathrm{Na}^{+}$, and creatinine excretion rates and that of Durs showed that only $\mathrm{K}^{+}$ values significantly $(P<0.02)$ improved the regression between Durs and creatinine excretion rates: Durs $=32.3+$ $355.7 \mathrm{~K}^{+}+29.1$ creatinine $(\mathrm{n}=80, r=0.435, P<0.001)$.

\section{Discussion}

This study confirms that urine from healthy adult subjects contains higher Dus concentrations than do the corresponding plasma samples. The greater amounts of Dus in urine samples permit a better precision of assay. In addition, because the DLIS/CR ratio for an untimed morning urinary sample (sample 0 of this study) correlates positively $(r=$ $0.819, P<0.001$ ) with the ratio for the complete 24-h collection, one can simply collect the first morning urine and validly use it to estimate the daily excretion of Durs. However, a complete 24-h collection is necessary for accurate determination of the mean urinary excretion of Dus during the day.

Here, we measured Dus values with a very sensitive RIA method specifically developed in our laboratory for assay of digoxin-like immunoreactivity (6-8). As previously reported for plasma extracts from adults, pregnant women, and newborns, the results obtained with this RIA method correlate well with those obtained with a radioreceptor assay involving the binding of $\left[{ }^{3} \mathrm{H}\right]$ ouabain to erythrocytes (13). This correlation might suggest that our RIA detects, to some extent, substances with immunological and biological activity similar to cardioactive glycosides.

Our data indicate that urinary excretion of an endogenous factor (or a group of substances) with digoxin-like immunoreactivity is higher during the "active" hours of the day, especially in the afternoon, than at rest during the night. Strenuous physical activity (14), infusion of saline solution (15), and high-sodium diet (16) have been previously reported to increase concentrations of Dus plasma or urine of normal subjects and hypertensive patients. Significant positive correlations between urinary Dus and creatinine concentrations (and excretion rates) have been found in our study, as previously reported for samples from newborns and boys $(9,10)$. Together, these findings suggest that the urinary excretion of Dus is to some extent dependent on glomerular filtration rate, which in turn accords with the hypothesis that Dus is an ultrafiltrable substance with a low 
molecular mass $(1,3,5,17)$. The increase in the glomerular filtration rate and diuresis may explain a greater urinary excretion of Dus during the day as compared with at rest, as also previously suggested by other authors (18) who reported a correlation between the presence of digoxin-like immunoactivity in urine and induced diuresis in normal individuals.

We also found weak, but significant, positive correlations between urinary DuIs excretion rate and the respective rates for $\mathrm{K}^{+}$and $\mathrm{Na}^{+}$. These data accord well with the findings of Gault et al. (15), who reported that plasma Dus correlated positively with urinary sodium excretion in 12 hypertensive patients before and after infusion of saline solution, and of Ebara et al. (19), who found a positive correlation between serum Dus values and the fractional excretion of $\mathrm{Na}^{+}$in 53 paired samples of infants. However, in the present study, using a stepwise multiple-regression analysis, only urinary $\mathrm{K}^{+}$, not $\mathrm{Na}^{+}$values, significantly improved the regression between urinary Dus and creatinine excretion rates in normal adults. Further studies are needed to elucidate the relationships between urinary Dus and electrolyte excretions.

This work was performed in the context of the Ricenca Finalizzata della Regione Toscana. In addition, it was supported in part by a grant (84.02442.56) from the National Research Council and by a grant from the Ministero della Pubblica Istruvione (Ricerca Scientifica 1985).

\section{References}

1. Valdes Jr R. Endogenous digoxin-like immunoreactive factors: impact on digoxin measurements and potential physiological implications [Review]. Clin Chem 1985;31:1525-32.

2. Soldin SJ. Digoxin-issues and controversies [Review]. Clin Chem 1986;32:5-12.

3. Clerico A, Ghione S, Balzan S, Del Chicca MG. Digoxin-like immunoreactive substance: non-specific interference or a new hormone? [Review]. J Nucl Med All Sci 1984;28:297-301.

4. De Wardener HE, Clarkson EM. Concepts of natriuretic hormone [Review]. Physiol Rev 1985;65:658-759.

5. Cloix JF, Crabos M, Wainer IW, et al. High-yield purification of urinary $\mathrm{Na}^{+}$-pump inhibition. Biochem Biophys Res Commun $1985 ; 131: 1234-40$.

6. Clerico A, Ghione S, Del Chicca MG, Balzan S. Problems in standardization of digitalis-like substance assays by means of competitive immunological methods [Letter]. Clin Chem 1987;33:340-1.

7. Balzan S, Clerico A, Del Chicca MG, et al. Digoxin-like immunoreactivity in normal human plasma and urine, as detected by a solid-phase radioimmunoassay. Clin Chem 1984;30:450-1.

8. Clerico A, Del Chicca MG, Montereggi A, et al. Digoxin-like immunoreactivity in human body fluids. $J$ Nucl Med All Sci 1985;29:305-12.

9. Balzan S, Clerico A, Malatino L, et al. Cardiac glycoside-like substance(s): correlations with urinary electrolysis in newborns and in boys. $J$ Nucl Med Allied Sci 1986;30:205-7.

10. Clerico A, Boldrini A, Del Chicca MG, et al. Correlations between digoxin-like immunoreactivity and electrolyte values in urinary samples of newborns. Biol Neonate 1986;50:27-35.

11. Pilo A, Zucchelli GC. Automatic treatment of radioimmunoassay data: an experimental validation of the results. Clin Chim Acta 1975;64:1-4.

12. Pilo A, Zucchelli GC, Malvano R, Masini S. Main features of computer algorithms for RIA data reduction. Comparison of some different approaches for the interpolation of dose-response curve. J Nucl Med Allied Sci 1982;26:235-48.

13. Balzan S, Ghione S, Clerico A, Montali U. Correlation between endogenous digoxin-like immunoreactivity and ${ }^{3} \mathrm{H}$-ouabain displacement on erythrocyte membranes in extracts of human plasma. Clin Biochem 1986;19:311-4.

14. Valdes Jr R, Hagberg JM. Exercise-induced elevation of endogenous digoxin-like immunoactive factor in human serum [Abstract]. Clin Chem 1985;31:1008.

15. Gault MH, Vasdev SC, Longerich LL, et al. Plasma digitalislike factor(s) increase with salt loading [Letter]. N Engl J Med 1983;309:1459.

16. Klingmiller D, Weiler E, Kramer HJ. Digoxin-like natriuretic activity in the urine of salt loaded healthy subjects. Klin Wochenschr 1982;60:1249-53.

17. Valdes Jr R, Graves S, Becker SL. Protein binding of endogenous digoxin-immunoreactive factors in human serum and its variation with clinical condition. J Clin Endocrinol Metab 1985;60:1135-43.

18. Valdes Jr R, Siegfried B. Digoxin immunoactivity in urine of persons not taking digoxin [Abstract]. Clin Chem 1983;29:1166.

19. Ebara H, Suzuki S, Nagashima K, et al. Digoxin-like immunoreactive substances in urine and serum from preterm and term infants: relationship to renal excretion of sodium. J Pediatr 1986;108:760-2. 